\title{
Pendekatan Model Predictive Control untuk Optimalisasi Biaya Penyediaan Vaksin dengan Reorder Point
}

\author{
Lenny Margaretta Huizen ${ }^{* 1}$, Titis handayani" ${ }^{\# 2}$, Rastri Prathivi ${ }^{* 3}$ \\ *Progran Studi Teknik Informatika, Fakultas Teknologi Informasi dan Komunikasi, Universitas Semarang \\ Jl. Soekarno-Hatta Tlogosari, Kota Semarang, 50196 \\ liennyeusm.ac.id \\ ${ }^{3}$ vivilusm.ac.id \\ \#Progran Studi Sistem Informatika, Fakultas Teknologi Informasi dan Komunikasi, Universitas Semarang \\ Jl. Soekarno-Hatta Tlogosari, Kota Semarang, 50196 \\ 2titisausm.ac.id
}

\begin{abstract}
Abstrak
Pengendalian persediaan sangat penting bagi penyedia barang, tujuannya adalah agar terjadi keseimbangan antara persediaan dan permintaan. Pengelolaan persediaan pada rumah sakit sangat penting untuk diperhatikan agar kebutuhan kesehatan tetap terpenuhi. Salah satu kebutuhan yang harus terpenuhi adalah vaksin. Pengelolaan persediaan vaksin yang benar diperlukan agar terhindar dari kekurangan stok yang dapat menyebabkan aktifitas pelayanan menjadi terganggu dan sebaliknya jika suatu persediaan terlalu banyak dapat terjadi kelebihan biaya seperti biaya pembelian, penyimpanan serta pemeliharaan. Model Predictive Control dapat digunakan untuk menganalisa pengendalian stok berdasarkan biaya yang optimal karena Model Predictive Control merupakan sistem kendali dengan menggunakan hasil perhitungan prediksi dalam mengeluarkan kontrol input. Untuk mencari biaya yang minimal yaitu berdasarkan tingkat persediaan vaksin serta biaya vaksin sehingga dapat menjamin ketersediaan vaksin. Hasil yang didapat adalah biaya yang dikeluarkan untuk penyediaan vaksin dengan menggunakan pendekatan MPC sebesar Rp 61.886 .332 berdasarkan jumlah pembelian vaksin 61 ampul lebih sedikit dibandingkan dengan rumah sakit sebesar Rp 64.007.000 atau sebesar pembelian 67 ampul. Hal ini tentu saja dapat mengurangi biaya untuk pengadaan vaksin.
\end{abstract}

Kata kunci: Model Predictive Control, Reorder Point, Vaksin

\section{Model Predictive Control Approach to Optimize Cost of Vaccines with Reorder Point and Safety Stock}

\begin{abstract}
The Inventory control is very important for providers of goods, the goal is to create a balance between supply and demand. Supply management at the hospital is very important to pay attention to so that health needs are still met. One of the needs that must be met is a vaccine. Management Correct supply of vaccines is needed in order to avoid stock shortages which can cause service activities to be disrupted and vice versa if there is too much of an excess cost, such as purchase, storage and maintenance costs. The Predictive Control Model can be used to analyze stock control based on optimal costs because the Predictive Control Model is a control system using the results of predictive calculations to issue input controls. To find minimal costs, namely based on the level of vaccine supplies and the cost of vaccines so as to guarantee the availability of vaccines. The results obtained were the costs incurred for the provision of vaccines using the MPC approach of Rp. 61,886,332 based on the purchase of 61 of vaccine, less than the hospital's Rp. $64,007,000$ or as much as the purchase of 67 . This of course can reduce the cost of procuring vaccines.
\end{abstract}

Keywords: Model Predictive Control, Reorder Point, Vaccines

\section{Pendahuluan}

Pengendalian persediaan sangat penting bagi peyedia barang. Pentingnya mengendaliakan suatu persediaan untuk dikelola adalah agar terjadi keseimbangan antara persediaan dan permintaan. Karena tanpa pengendalian yang tepat maka akan terjadi masalah dalam pemenuhan kebutuhan konsumen [1]. Tujuan lainnya dalam adanya suatu perencanaan dalam pengendalian suatu barang dimaksudkan agar dapat meminimumkan biaya persediaan. Jika suatu persediaan mempunyai jumlah yang terlalu besar maka akan terjadi suatu pemborosan dalam hal pembelian, penyimpanan serta pemeliharaan suatu persediaan, dan 
sebaliknya jika jumlah suatu persediaan mempunya jumlah yang terlalu sedikit maka tidak menutup kemungkinan suatu konsumen akan berlaih ke penyedia lain yang menyediaan barang tersebut. Pada rumah sakit, pengelolaan persediaan sangat penting agar kebutuhan kesehatan tetap terpenuhi. Salah satunya adalah vaksin karena akan mendukung pelayanan imunisasi.

Untuk mengetahui perhitungan dalam suatu pengendalian persediaan vaksin maka diperlukan suatu pendekatan posisi aman agar tersedianya persediaan vaksin. Dalam menentukan berapa jumlah stok aman maka dilakukan penentuan batas minimal dalam persediaan barang pada bagian gudang farmasi. Metode Reorder Point merupakan suatu titik dimana harus dilakukan pemesanan kembali agar jumlah persediaan barang tetap terpenuhi.

Model Predictive Control digunakan untuk menganalisa pengendalian stok berdasarkan biaya yang optimal karena Model Predictive Control merupakan sistem kendali dengan menggunakan hasil perhitungan prediksi dalam mengeluarkan kontrol input. Cara kerja dari Model Predictive Control yaitu dengan mencari berapa biaya optimum berdasar tingkat persediaan obat, pesanan obat dan biaya obat [2]. Untuk mencari biaya yang minimal berdasarkan tingkat persediaan vaksin serta biaya vaksin sehingga dapat menentukan tingkat persediaan vaksin dan dapar menjamin ketersediaan vaksin.

\section{METODOLOGI}

Persediaan mempunyai peran yang penting dalam manajemen suatu rumah sakit karena dipengaruhi oleh tingkat konsumsi dan biaya pembelian [3].Manajemen persediaan yang efektif memerlukan pengawasan serta pengaturan prioritas dalam setiap pembelian serta pendistribusian obat-obatan [3] Jumlah persediaan obat pada bagian farmasi tergantung pada permintaan dan pesanan, sehingga jumlah persediaan pada masing masing obat akan berbeda. Jumlah persediaan yang optimal dapat menyebabkan biaya yang dikeluarkan menjadi optimal. Jumlah persediaan dinyatakan dengan si, nilai si didapat dari jumlah persediaan yang ada pada saat ini, sedangkan jumlah persediaan untuk waktu berikutnya maka dinyatakan dengan si(t+1), sehingga untuk menghitungnya digunakan Persamaan 1 [2],

$$
s i(t+1)=s i(t)+o i(t-\tau i)-d i(t)
$$

\section{A. Reorder Point}

Jumlah persediaan harus tetap ada pada saat dilakukan pemesanan [4]. Reorder point merupakan suatu titik pemesanan kembali yang dimana adalah tindakan yang dilakukan untuk mengisi persediaan barang. Persamaan yang digunakan sesperti Persamaan 2:

$R O P=(d \times L)+S S$

dimana ROP adalah reorder point (titik pemesanan kembali), $d$ adalah rata-rata permintaan, sedangkan $\mathrm{L}$ adalah lead time serta SS adalah safety stock. Untuk mencari nilai d adalah dengan Persamaan 3.
$d=\frac{D}{\text { jumlah hari kerja per periode }}$

Dimana D adalah permintaan

\section{B. Safety Stock}

Safety stock (SS) merupakan persediaan tambahan yang dilakukan untuk menghindari kokosongan stok, safety stock berbeda dengan reorder point. Tujuan dari safety stock adalah melindungi persediaan dari berbagai penyimpangan seperti tanggal pengiriman, variasi kebutuhan, jumlah pengiriman serta variasi inventaris, perhitungan stok aman didapatkan dari persamaan 4 [5]

$S S=Z * \sigma L T D$

dimana Z merupakan service factor dan $\sigma$ LTD merupakan standar deviasi permintaan harian.

\section{Standar Deviasi}

Standar Deviasi $(\sigma)$ merupakan ukuran variasi, nilai бLTD merupakan Standar Deviasi permintaan harian, nilai ini didapat dengan Persamaan 5 :

Standard deviation $(\sigma)=\sqrt{\frac{1}{n}} \sum_{i=1}^{n}\left(d_{i}-\overline{\mathrm{d}}\right)$

dengan di merupakan permintaan pada periode $\mathrm{i}$, $\overline{\mathrm{d}}$ merupakan permintaan rata-rata dan $\mathrm{n}$ adalah jumlah data.

\section{Model Predictive Control}

Penelitian ini merupakan penelitian lanjutan mengenai optimasi biaya. Pada penlitian sebelumnya dengan menggunakan pendekatan melalui Reorder point dan Economic Order Quantity maka dapat didapatkan berapa jumlah pesanan yang akan dipesan serta dapat menentukan pada jumlah persediaan berapa dapat dilakukan pesanan kembali, sehingga dengan melakukan kedua pendekatan ini dapat mengurangi biaya penyimpanan, pembelian dan pesanan. Sehingga dengan hal ini dapat menghindarkan dari kelebihan serta kekurangan persediaan.

Untuk melakukan pesanan obat mempunyai persyaratan yaitu mencari nilai minimal Cost Function (J) untuk pesanan (o) yang menyangkut jumlah persediaan, biaya dan pesanan, diberikan pada Persamaan 6, [2]

$\min _{o} J=\beta_{1} J_{1}(o, t)+\beta_{2} J_{2}(o, t)+\beta_{3} J_{3}(o, t)$

\section{Dimana}

$\mathrm{J}_{1}$ : level stok pada saat pemesanan

$\mathrm{J}_{2}$ : merupakan beban biaya pemesanan

$\mathrm{J}_{3}$ merupakan pesanan yang dilakukan.

$\beta 1, \beta 2$, dan $\beta 3$ : merupakan bobot yang diberikan pada masing-masing $\mathbf{J}_{1}, \mathbf{J}_{2}$, dan $\mathbf{J}_{3}$. Pembobotan ini ditentukan oleh seberapa penting tujuan dari masing-masing bagian, sehingga mempunyai bobot yang konstan untuk tujuan manajemen. Sehingga untuk mencari nilai pada masing 
masing $\mathbf{J}_{1}, \mathbf{J}_{2}, \mathbf{J}_{3}$ dilakukan dengan Persamaan 7, 8 dan 9 [2]:

$$
\begin{aligned}
& J_{1}=\min _{\delta_{i}, \mathrm{o}_{1} \forall i} \sum_{k=0}^{N} \sum_{i=1}^{N_{i}} C_{0, i} s_{i}(t+k) \\
& \mathrm{J}_{2}=\min _{\delta \mathrm{i}, \mathrm{o} 1 \forall \mathrm{i}} \sum_{\mathrm{k}=0}^{\mathrm{N}} \sum_{\mathrm{i}=1}^{\mathrm{N}_{\mathrm{i}}} \mathrm{P}_{\mathrm{i}} \delta_{\mathrm{i}}(\mathrm{t}+\mathrm{k}) \mathrm{o}_{\mathrm{i}}(\mathrm{t}+\mathrm{k}) \\
& J_{3}=\min _{\delta i} \sum_{k=0}^{N} \sum_{i=1}^{N_{i}} C_{o p, i} \delta_{i}(t+k)
\end{aligned}
$$

dengan Coi merupakan biaya simpan obat untuk jumlah persediaan $\left(\mathrm{s}_{\mathrm{i}}\right)$ yang dipesan pada waktu $\mathrm{t}$, jumlah persediaan yang ada merupakan hasil dari jumlah maksimal persediaan kemudian dikurangkan dengan jumlah safety stock sehingga menghasilkan jumlah persediaan yang baru. Pi merupakan harga obat yang dipesan dinyatakan dengan $\delta_{\mathrm{i}}$ pada saat melalukan pemesanan sedangkan. $\mathrm{C}_{\mathrm{op}, \mathrm{i}}$ merupakan biaya pemesanan obat untuk setiap adanya transaksi pemesanan.

\section{HASIL DAN PEMBAHASAN}

Data permintaan, dan data persediaan kemudian diolah untuk mendapatkan sebuah Informasi yang diperlukan untuk penelitian.

\section{A. Lead Time}

Pada pengolahan data hal pertama yang dilakukan adalah menentukan berapa lama waktu yang diperlukan dari sebuah pesanan untuk sampai ke gudang farmasi. Waktu yang didapatkan adalah 1 hari karena supplier untuk gudang farmasi berada pada kota yang sama.

\section{B. Menghitung Safety Stock}

Perhitungan jumlah persediaann yaitu dengan mencari nilai Z (Service Level) yang dapat dilihat pada Tabel 1 dan $\sigma$ LTD (standar deviasi). Service level ditempatkan pada penelitian adalah $95 \%$ artinya untuk tingkat pelayanan dapat ditempatkan pada angka 95\% dan untuk kehabisan stock pada angka $5 \%$. Angka $95 \%$ merupakan probabilitas distribusi yang biasa digunakan.

Dari tabel distribusi normal service level ditempatkan pada angka 95\% sehingga service level terletak pada 1,6. Setelah mendapatkan nilai service level dan service faktor kemudian adalah menghitung nilai dari standar deviasi $(\sigma)$ yang merupakan ukuran variasi. Nilai oLTD merupakan standar deviasi dari perimtaan mingguan. Untuk menghitung nilai dari standar deviasi ada beberapa langkah seperti, mempersiapkan data permintaan secara mingguan, kemudian menghitung rata-rata permintaan,mengurangkan setiap data dengan rata-rata permintaan kemudian barulah dikuadratkan dan menjumlahkan semua hasil kuadrat. Standar deviasi yang diperoleh untuk vaksin hexaxim adalah sebesar 3,16 .

Setelah service faktor dan standar deviasinya didapatkan maka nilai dari safety stock yang didapatkan untuk Hexaxim sebesar 5 kemudian menghitung pemakaian ratarata.

\section{Menghitung rata-rata permintaan mingguan}

Untuk menghitung permintaan rata-rata dari vaksin hexaxim yaitu dengan menggunakan Persamaan 6, sehingga akan mendapatkan hasil yaitu 3,5.

\section{Menghitung Reorder Point}

Perhitungan reorder point digunakan untuk mendapatkan nilai trayektori acuan yang digunakan pada Model Predictive Control. Nilai ini digunakan agar dapat mengetahui kapan sebaiknya sebuah pesanan dilakukan. Untuk mendapatkan nilai Reorder Point maka digunakan Persamaan 2, sehingga didapatkan nilai 7.

\section{E. Model Predictive Control (MPC)}

Penggunaan pendekatan dengan menggunakan MPC dilakukan agar dapat mengetahui berapa jumlah biaya keseluruhan yang dikeluarkan untuk setiap pesanan yang akan dilakukan. Nilai ini didapatkan dengan mencari berapa jumlah stok pada saat dilakukan pesanan, biayabiaya apa saja yang ikut terhitung dalam melakukan pesanan dan berapa jumlah pesanan yang dipesan.

Untuk mencari berapa jumlah biaya yang akan dikeluarkan pada saat dilakukan pesanan pada waktu $t$ dapat dilihat perhitungan dengan menggunakan contoh Tabel I persediaan untuk vaksin Hexaxim.

TABEL I

DATA PERSEDIAAN VAKSIN HEXAXIM DI RUMAH SAKIT

\begin{tabular}{|c|c|c|c|c|}
\hline $\begin{array}{c}\text { Minggu } \\
\text { Ke }\end{array}$ & Persediaan & Pesanan & Permintaan & Jumlah \\
\hline 1 & 10 & 0 & 0 & 10 \\
\hline 2 & 10 & 0 & 2 & 8 \\
\hline 3 & 8 & 5 & 3 & 10 \\
\hline 4 & 10 & 0 & 0 & 10 \\
\hline 5 & 10 & 0 & 0 & 10 \\
\hline 6 & 10 & 0 & 6 & 4 \\
\hline 7 & 4 & 10 & 5 & 9 \\
\hline 8 & 9 & 0 & 0 & 9 \\
\hline 9 & 9 & 6 & 9 & 6 \\
\hline 10 & 6 & 6 & 2 & 10 \\
\hline 11 & 10 & 0 & 2 & 8 \\
\hline 12 & 8 & 10 & 8 & 10 \\
\hline 13 & 10 & 0 & 6 & 4 \\
\hline 14 & 4 & 10 & 0 & 14 \\
\hline 15 & 14 & 0 & 3 & 11 \\
\hline 16 & 11 & 0 & 0 & 11 \\
\hline 17 & 11 & 0 & 7 & 4 \\
\hline 18 & 4 & 20 & 7 & 17 \\
\hline 19 & 17 & 0 & 0 & 17 \\
\hline & & & & 60 \\
\hline
\end{tabular}

Pada saat tanggal 6 Desember dengan jumlah persediaan 6 dimana sehingga nilai $\mathrm{J}_{1}$ diperoleh sebesar 226.448. Sedangkan untuk menghitung biaya yang dikeluarkan untuk pembelian vaksin Hexaxim sebesar 3.800.000.

Karena Biaya pesan tidak terpengaruh pada jumlah vaksin yang dipesan maka perhitungan yang didapat adalah sebesar 1 .

Setelah mendapatkan nilai pada $\mathrm{J}_{1} . \mathrm{J}_{2}, \mathrm{~J}_{3}$ maka persamaan MPC yang didapatkan adalah sebagai berikut dengan nilai $\beta_{1}, \beta_{2}, \beta_{3}$ adalah 1 karena Pembobotan ini ditentukan oleh seberapa penting tujuan dari masingmasing bagian, sehingga mempunyai bobot yang konstan untuk tujuan manajemen sehingga didapatkan nilai

$$
\begin{aligned}
\min _{o} J & =\beta_{1} J_{1}(o, t)+\beta_{2} J_{2}(o, t)+\beta_{3} J_{3}(o, t) \\
& =(1 *(56.612 * 4))+(1 *(950.000 * 4))+(1 *(21000 * 1)) \\
& =226.448+3.800 .000+21.000 \\
& =4.047 .448
\end{aligned}
$$




\section{F. Perhitungan Akurasi}

Perhitungan akurasi dilakukan dengan membandingkan hasil perhitungan rumah sakit dengan penelitian, sehingga hasil yang didapat adalah seperti pada Tabel II untuk vaksin Hexaxim.

TABEL II

DATA PERSEDIAAN PERBANDINGAN BIAYA YANG DIKELUARKAN ANTARA RUMAH SAKIT DAN PENELITIAN VAKSIN HEXAXIM

\begin{tabular}{|c|c|cc|}
\hline Kesimpulan & Rumah Sakit & \multicolumn{2}{|c|}{ ROP } \\
\hline Jumlah Pembelian & 67 & \multicolumn{2}{|c|}{62} \\
\hline $\begin{array}{c}\text { Biaya Pembelian } \\
\text { Vaksin }\end{array}$ & $\begin{array}{c}\mathrm{Rp} \\
63.650 .000,00\end{array}$ & $\mathrm{Rp}$ & $58.900 .000,00$ \\
\hline $\mathrm{Rp}$ & $\mathrm{Rp}$ & $3.509 .944,00$ \\
\hline Biaya Simpan & $210.000,00$ & $\mathrm{Rp}$ & \\
\hline Biaya Pesan & $111.000,00$ & $\mathrm{Rp}$ & $273.000,00$ \\
\hline Jumlah & $63.971 .000,00$ & $\mathrm{Rp}$ & $62.682 .944,00$ \\
\hline $\begin{array}{c}\text { selisih DENGAN } \\
\text { RS }\end{array}$ & $\mathrm{Rp}$ & $\mathrm{Rp}$ & $1.288 .056,00$ \\
\hline
\end{tabular}

\section{KESIMPULAN}

Kesimpulan yang didapat dari penelitian ini adalah dengan penggunaan Model Predictive Control akan diketahui berapa biaya yang akan dikeluarkan setiap akan melakukan pemesanan dengan memanfaatkan Reorder point sebagai trayektori acuan yang digunakan agar dapat mengetahui kapan akan dilakukan pemesanan vaksin.

Hasil yang didapat adalah biaya yang dikeluarkan untuk penyediaan vaksin dengan menggunakan pendekatan MPC sebesar Rp 61.886.332 berdasarkan jumlah pembelian vaksin 61 ampul lebih sedikit dibandingkan dengan rumah sakit sebesar Rp 64.007.000 atau sebesar pembelian 67 ampul. Hal ini tentu saja dapat mengurangi biaya untuk pengadaan vaksin.

\section{UCAPAN TERIMA KASIH}

Ucapan terima kasih kepada Lembaga Penelitian dan Pengabdian masyarakat (LPPM) Universitas Semarang atas sumber dana penelitian dengan nomor kontrak : 057/UAM.H7.LPPM/L/2020.

\section{DAFTAR PUSTAKA}

[1] F. Sulaiman and N.Nanda.2016. Pengendalian Persediaan Bahan Baku Dengan Menggunakan Metode EOQ Pada UD. Adi Mabel. Jurnal Teknovasi,2(1),pp11.

[2] J. Maestre, M. Fernandez, and I.Jurado. 2018. An application of economic model predictive control to inventory management in hospitals. Control Engineering Practice. 71.pp 120-128.

[3] D. Singh, A. Verma.2018. Inventory Management in Supply Chain. Materials Today: Proceedings. 5(2).pp.3867-3872.

[4] D. Sjahrial.2012. PengantarManajemen Keuangan, Jakarta, Penerbit Mitra Kencana Media.

[5] Radasanu, A., 2016. Inventory Management, Service Level and Safety. Journal of Public Administratiom, 9, pp.145-153. 